\title{
2017 Katalan Bağımsızlık Referandumu ve Katalonya Parlamentosu'nun Bağımsızlık İlanına Yönelik Uluslararası Tepkiler
}

\author{
Sinem ÇELIK ${ }^{a}$
}

\section{Özet}

1 Ekim 2017'de düzenlenen Katalan Bağımsızlık Referandumu, gerek İspanya merkezi hükümeti gerekse Katalonya açısından son dönemlerin en önemli gelişmelerinden biri olmuştur. Katalonya'nın referandum sonrası 27 Ekim 2017'de gerçekleştirdiği tek taraflı bağımsızlık ilanı, İspanya'nın toprak bütünlüğünün ve ülkesel birliğinin bozulması ihtimalini ortaya çıkardığından İspanya merkezi hükümeti tarafından endişeyle karşılanmıştır. İspanya merkezi hükümeti ile Katalonya özerk hükümeti arasında yaşanan bu önemli sorun, dünyadaki diğer ayrılıkçı bölgeleri harekete geçirme olasılığı taşıdığından diğer devletler tarafından da yakından takip edilmiş, uluslararası arenada oluşan tepkiler art arda kamuoyuyla paylaşılmıştır. Bu çalışmada, 2017'de düzenlenen Katalan Bağımsızlık Referandumu genel hatlarıyla ele alınmış, söz konusu referandum akabinde Katalan Parlamentosu tarafından ilan edilen tek taraflı bağımsızlığa ilişkin verilen uluslararası tepkiler incelenmiştir. Çalışma, 2017 Katalan referandumunun hangi koşullarda ve nasıl bir ortamda gerçekleştiğini açıklamak ve referandumu takiben verilen bağımsızlık kararına dünyadan gelen ilk tepkilerin neler olduğunu analiz etmek amacını taşımaktadır.
Anahtar Kelimeler

Katalonya

İspanya

2017 Katalan Bağımsızlık

Referandumu

Uluslararası Tepkiler

Makale Hakkında

Geliş Tarihi: 24.01.2020

Kabul Tarihi: 26.03.2021

Doi: $10.18026 /$ cbayarsos.679490

\section{Catalan Independence Referendum 2017 and International Reactions to the Catalan Parliament's Declaration of Independence}

\begin{abstract}
The Catalan independence referendum on October 1st, 2017 is one of the most important developments in recent times for both the Spanish central government and Catalonia. As the unilateral declaration of independence of Catalonia after the referendum on October 27, 2017, threatened the territorial integrity and unity of Spain, the Spanish central government was concerned. This important problem between the Spanish central government and the autonomous government of Catalonia has been followed closely by other states as it could mobilize other separatist regions of the world. In this regard, many reactions at the international level have been shared with the public in turn. This study dealt with the Catalan independence referendum held in 2017 in general and it is examined the international reactions to the unilateral declaration of independence by the Catalan parliament after the referendum. The study aims to explain the conditions and context of the 2017 Catalan referendum, as well as to analyze the world's first reactions to the independence decision made after the referendum.
\end{abstract}

Keywords

Catalonia

Spain

Catalan Independence

Referendum 2017

International Reactions

About Article

Received: 24.01.2020

Accepted: 26.03 .2021

Doi: 10.18026/cbayarsos.679490

a Arş. Gör., Karadeniz Teknik Üniversitesi, Uluslararası İlişkiler Bölümü, sinem.tan@ktu.edu.tr, ORCID ID: 0000-0001-9473-9401. 


\section{Giriş}

Ekim 2017'de, bölgesel Katalonya hükümeti, İspanya merkez hükümetinin sıkı muhalefetine ve İspanya Anayasa Mahkemesi'nin kararlarına rağmen, Katalonya'nın İspanya'dan bağımsızlığı konusunda bir referandum düzenlemiştir. 5,3 milyon seçmenin kayıtlı olduğu bölgede 2,3 milyon geçerli oy kullanılmış, dolayısıyla katılım \% 43 oranında gerçekleşmiştir. Oy kullananların \% 90,9'u "Katalonya'nın Cumhuriyet formunda bağımsız bir ülke olmasını ister misiniz" sorusuna "evet" cevabını verirken, \% 7,87'lik bir kısım ise "hayır" cevabını vermiştir. Her ne kadar katılımın düşük olduğunu söylemek mümkünse de sonuçlar itibariyle gerçekleştirilen referandum, bağımsızlık yanlıları tarafından bir zafer olarak görülmüştür.

Referandumun hemen ardından, Katalan parlamentosu gizli bir oylama gerçekleştirerek 27 Ekim 2017'de tek taraflı olarak bağımsızlık ilan etmiştir. Buna karşılık, İspanya hükümeti Katalonya'nın siyasi özerkliğini askıya alarak Katalan hükümetini ve parlamentosunu dağıtmış, Katalan Parlamentosu için erken seçim çağrısı yapmıştır. Referandumu takiben gerçekleşen tek taraflı bağımsızlık ilanının ardından İspanya merkezi hükümeti ve diğer resmi organların yanı sıra uluslararası alanda da çok sayıda tepkiler gelmiştir. Katalonya'daki hükümet ve hükümet dışı organizasyonlar referandumu ve sonrasında gerçekleşen bağımsızlık ilanını savunurken, uluslararası arenada yer alan devletlerin pek çoğu İspanya'nın “toprak bütünlüğünü” ve "ülkesel birliğini” savunmuştur.

Bu çalışmada, konuya ilişkin kavramsal çerçeve ile 2017 Katalan Bağımsızlık Referandumu ve referandumu takip eden süreç içinde gerçekleşen tek taraflı bağımsızlık ilanı genel hatlarıyla ele alındıktan sonra, Katalonya Parlamentosu'nun bağımsızlık ilanına yönelik gösterilen uluslararası tepkilerin neler olduğunun analiz edilmesi amaçlanmıştır. Çalışma kapsamında, İspanya merkezi hükümetinin referanduma ve bağımsızlık ilanına gösterdiği tepkilerin yanında $A B, A B D$, Çin, Rusya ve İngiltere gibi küresel aktörler başta olmak üzere çeşitli devletlerin meseleye verdiği tepkiler incelenmiştir. Çalışma, Katalonya'nın bağımsızlık ilanı karşısında gösterilen uluslararası tepkilerin temelinde neler olabileceğini ve bu tepkilerin farklılaşıp farklılaşmadığını ya da aynı düzeyde olup olmadığını ortaya koymak amacı da gütmektedir.

\section{Kavramsal Çerçeve}

Katalan Bağımsızlık Referandumu ve sonrasında Katalonya'nın ilan ettiği bağımsızlığa ilişkin değerlendirmelerde bulunmadan önce kavramsal arka plandan bahsetmek konunun daha iyi anlaşılması açısından önemlidir. Bilindiği gibi self-determinasyon ve ayrılma kavramları özellikle 20. yüzyılın önemli konuları arasında yer almaktadır. Selfdeterminasyon ve ayrılma kavramları birbiriyle ilişkili kavramlardır. Self-determinasyon kavramı; bazı kesimlerce ana devletten ayrılma yoluyla bağımsızlık kazanma şeklinde ifade edilirken, kimi kesimler tarafından otonomi veya özerklik elde etmeye ilişkin bir araç olarak yorumlanmaktadır. Ana devletten ayrılma yoluyla bağımsızlık elde etmek selfdeterminasyonun dişsal boyutunu oluştururken, otonomi ya da özerklik kazanmak ise selfdeterminasyonun içsel boyutunu oluşturmaktadır.

Self-determinasyonun dişsal boyutu olarak değerlendirilen ayrılma olgusu; ana devlet varlığını sürdürmeye devam ederken, ana devletin topraklarının bazı bölümünün geri çekilmesi ve buna bağlı olarak diğer bir devletin oluşması eylemini ifade etmektedir (Van den Driest, 2013). Crawford (2006), self-determinasyonun bir modu olan ayrilma olgusunun 
rıza boyutuna vurgu yaparak ayrılmayı "egemen bir devletin rızası olmaksızın kuvvet kullanma ya da tehdidi yoluyla diğer yeni bir devletin kurulması" olarak tanımlamıştır. Kohen (2006)'e göre ayrılma, “önceki ana devletin rızası bulunmadan, bir bölgenin topraklarının bir kısmı ile nüfusunun bir bölümünün ayrılması sonucunda yeni bir bağımsız varlığın ortaya çıkması" anlamına gelmektedir.

Uluslararası literatürde ayrılma hakkı, temel olarak iki kategoriye ayrılmaktadır. Bunlar; rızaya dayanan ayrılma hakkı ile tek taraflı ayrılma hakkıdır. Rızaya dayalı ayrılma hakkı, bir müzakere süreci sonrasında ortaya çıkar ya da anayasal olarak kabul edilen sürece uygun bir biçimde kullanılır (Buchanan, 2007). Ayrıca ayrılma hakkının bu biçimi, büyük oranda bir hukuk meselesi olarak kabul edilir ve ayrılmanın anayasasını onaylamayı gerektirir (Muro, 2017). Tek taraflı ayrılma ise, önceki egemen devletin rızası bulunmaksızın bir devletin topraklarının bir bölümünün ayrılması olarak tanımlanmaktadır (Crawford, 2006). Tek taraflı ayrılmalarda ana devletin rızasının bulunmaması, bu tür ayrılmaların güç kullanımı ve tehdidi içerebileceği anlamına gelmektedir. Tek taraflı ayrılmayı gerçekleştirmek için girişimde bulunmaya ilişkin siyasi eylem, sivil itaatsizlik riskini arttırarak birçok sosyal, siyasal ve ekonomik sıkıntıyı beraberinde getirmektedir.

Katalonya Parlamentosu'nun bağımsızlık referandumu sonrasında gerçekleştirdiği bağımsızlık ilanı tek taraflı ayrılma kategorisi içerisinde değerlendirilmektedir. Nitekim 1978 İspanya Anayasası'na göre hem referandumu merkezi hükümetin izni olmadan organize edip gerçekleştirmek hem de bu referanduma dayanarak bağımsızlık ilan etmek yasal değildir. Dolayısıyla Katalonya'nın gerçekleştirdiği tek taraflı bağımsızlık ilanında ana devletin yani İspanya'nın rızası bulunmamaktadır. Genel anlamda tek taraflı olarak gerçekleştirilen ayrılmalarda ayrılan yeni devletin diğer devletler tarafından tanınmaması sorunu ortaya çıkmaktadır. Diğer devletlerce tanınmayan bir devletin karşılaşacağı problem ise oldukça fazladır. Bunlardan bazıları ise uluslararası kurumlara dâhil olamama, uluslararası anlaşmalar imzalayamama, normal ekonomik-diplomatik ilişkiler yürütememe ve uluslararası sözleşmelere taraf olamama şeklindedir (Fabry, 2012).

\section{Katalan Bağımsızlık Referandumu}

1 Ekim 2017'de Katalonya Özerk Bölgesi'nde, seçmenlere “Katalonya'nın Cumhuriyet ile yönetilen bağımsız bir ülke olmasını ister misiniz?" sorusunun sorulduğu bir bağımsızlık referandumu düzenlenmiştir. Katalan Bölgesel Hükümeti nihai katılımın \% 43 (2,3 milyon) olduğunu belirtmiş, oy kullananların \% 90,2'si'nin 'Evet', \% 7,8'inin 'Hayır' oyu verdiğini açıklamıştır (Cetra', Casanas-Adam ve Ta'rrega, 2018).

Katalan referandumunun altında yatan temel gerekçelere bakıldığında, öncelikle Katalonya'nın kendine ait ayrı bir tarihi, dili ve kültürü olduğunu söylemek mümkündür. Bu nedenle bağımsızlığı çevreleyen tartışmalarda kimlik büyük rol oynamaktadır. Diğer bir gerekçe, 1939-1975 yılları arasında Francisco Franco'nun askeri yönetimi altında Katalan kültürünün bastırılmış olmasıdır. Ancak bağımsızlık referanduma giden süreçte temel gerekçe, 2008 finansal krizi dolayısıyla İspanya'nın saplandığı borç batağıdır. Tam özerklik için yapılan baskı İspanya'nın 2008 borç krizinden bu yana hız kazanmıştır. Bağımsızlık yanlısı destekçiler, İspanya'nın en zengin bölgelerinden biri olan Katalonya'nın İspanya'ya Madrid'deki merkezi hükümetten daha fazla finansal destek sunduğunu iddia etmektedir (Child ve Mitchell, 2017). 
Söz konusu gerekçelere bağlı olarak gerçekleştirilen referandum, İspanya Yüksek Mahkemesi tarafından İspanya Anayasası uyarınca yasadışı ilan edilmiştir. Yargı makamına atıfta bulunan Madrid, oylama günü insanların oy kullanmasını önlemek için ulusal polisi devreye sokmak suretiyle ortak bir çaba başlatmıştır. İspanyol ulusal polisi, referanduma katılmaya çalışan protestoculara ve seçmenlere lastik mermiler atmış ve cop kullanmıştır. Polisler tarafından seçmenlerin saçlarından çekildiği ve yaşlıların zapt edildiği görülmüştür. Katalanları şok eden bu sahneler, Avrupa çapında da büyük yankı uyandırmıştır. Katalan yetkililer, yaklaşık 900 kişinin yaralandığını açılamıştır. Muhalefet partileri, İspanya Başbakanı Mariano Rajoy'u referandumu engellemeye yönelik sert yaklaşımından ötürü eleştirmiştir (Dewan, Cotovio ve Clarke, 2017).

$\mathrm{Bu}$ sicak atmosfer ortamında Katalan Parlamentosu, gizli gerçekleştirilen oylama (70 kişi lehte, 10 kişi aleyhte, 2 kişi çekimser) neticesinde 27 Ekim 2017'de İspanya'dan bağımsızlık ilan etmiştir. Bunun üzerine İspanya Başbakanı Rajoy'un, senatörlere "hukuk, demokrasi ve istikrarı Katalonya'da yeniden tesis etmek için bölgede doğrudan yönetime ihtiyaç duyulduğunu" söylemesi akabinde İspanya parlamentosu bölge üzerinde doğrudan yönetimi onaylamıştır (BBC, 2017). Ayrıca Anayasa'nın 155. maddesini işleterek Katalan Parlamentosunu feshettiğini bildiren Rajoy, Katalonya'da demokrasi ortamının yeniden oluşabilmesi açısından yasal ve özgür bir seçime ihtiyaç olduğunu ve bu nedenle 21 Aralık'ta erken seçim yapılacağını açıklamıştır (Real Instituto Elcano, 2019).

İspanya merkezi hükümeti tarafından böylesi sert önlemler alındığı sırada Katalonya Hükümet başkanı Carles Puigdemont Belçika'ya kaçmıştır. Geri kalan siyasi liderlerden 12'si hakkında "şiddet yoluyla anayasal düzeni kısmen ya da tamamen yıkmak", "kanunun uygulanmasını engellemek", "devlet kurumlarına itaatsiz davranmak" ve "kamu malını kötüye kullanmak" suçlarından 7 ile 25 yıl arasında hapis cezası istenmiştir. Ekim 2019'da sonuçlanan davada Katalan siyasi liderlerden 3'ü serbest bırakılırken, 9 kişi 9 ile 13 yıl arasında değişen hapis cezasına çarptırılmıştır. Bu gelişmeler bağımsızlık yanlısı Katalan halk tarafından öfkeyle karşılanmış ve siyasi liderlerin serbest bırakılmasına yönelik çeşitli protesto gösterileri gerçekleştirilmiştir (Minder, 2019).

Günümüzde, Katalan ve Madrid hükümetleri arasındaki ilişkilerde 2017 Katalan Bağımsızlık Referandumunun yarattığı gergin ortamın halen etkisini sürdürdüğü görülmektedir. Referandum sonrası bağımsızlık söylemlerinden asla vazgeçmeyen ayrılıkçı Katalanlar, düzenledikleri çeşitli protesto gösterileri aracılığıyla, bağımsızlık yolunda her türlü baskı karşısında duracaklarının sinyalini vermektedirler. Bu şartlar altında, 2017 referandumunun ve akabinde gerçekleşen tek taraflı bağımsızlık ilanının yol açtığı söz konusu gergin atmosferin taraflar arasında ciddi bir uzlaşma sağlanana kadar süreceğini söylemek mümkündür.

\section{Katalonya Parlamentosu'nun Bağımsızlık İlanına Yönelik Uluslararası Tepkiler}

Katalonya'nın 1 Ekim 2017'de gerçekleştirdiği bağımsızlık referandumunu dayanak göstererek, 27 Ekim 2017'de İspanya'dan tek taraflı bağımsızlık ilan etmesine dünyadan tepkiler gecikmemiştir. ABD Dışişleri Bakanlığı, Katalonya Özerk Hükümeti'nin bağımsızlık ilan etmesinin ardından İspanya'nın bölgenin kontrolünü ele geçirme çabalarını desteklediğini açıklamıştır. ABD Dışişleri Bakanlığı sözcüsü Heather Nauert, Katalonya'nın İspanya'nın ayrılmaz bir parçası olduğunu vurgulamış, ABD'nin Madrid hükümetinin İspanya'yı güçlü ve birleşik tutmak için aldığı anayasal önlemlerini desteklediğini ifade 
etmiştir (Mix, 2018). Eylül 2017'de İspanya Başbakanı Mariano Rajoy ile düzenlediği ortak basın toplantısında Katalonya'nın bağımsızlık ilanının "aptalca" olacağını söyleyen ABD Başkanı Donald Trump, "Bence İspanya büyük bir ülke ve birleşik kalmalı" diyerek bağımsızlık ilanı öncesinde duruma yönelik yaklaşımını ortaya koymuştur (Weiss, 2017).

Katalan bağımsızlık referandumunun ikinci gününde, Avrupa Komisyonu ise konunun bir İspanyol iç meselesi olduğunu ve tüm eylemlerin İspanya Anayasası uyarınca yapılması gerektiğini açılayarak, tüm ilgili aktörlerin çok hızlı bir şekilde çatışmadan diyaloga geçmesi konusunda çağrıda bulunmuştur. Siyasette şiddete yer olmadığını vurgulayan Komisyon, "Başbakan Rajoy'un liderliğine, bu zor süreci İspanya Anayasası çerçevesinde çözme ve bölge vatandaşlarının temel haklarına saygı gösterme konusunda güveniyoruz" diyerek İspanya'nın birlik ve beraberliğinin korunması gerekliliğine duyduğu inanc ifade etmiştir (DW News, 2017). Komisyon Başkanı Jean- Claude Juncker, Avrupa Birliği'nin daha fazla bölünmeye ihtiyacı olmadığını belirterek, Katalonya'nın bağımsızlık ilanının boş bir çabadan ibaret olduğunu vurgulamıştır. Avrupa Konseyi Başkanı Donald Tusk ise, Katalan parlamentosunun tek taraflı bağımsızlık bildirisinin Avrupa Birliği açısından hiçbir şey ifade etmediğini belirtmiştir. Avrupa Parlamentosu Başkanı Antonio Tajani, Twitter'da yaptığı açıklamada Katalan referandumunu Avrupa Birliği'nden hiç kimsenin tanımayacağını ifade etmiştir (Aljazeera, 2017).

İngiltere Başbakanı Theresa May sözcüsü, Katalan parlamentosunun tek taraflı bağımsızlık ilanından sonra şu ifadeleri kullanmıştır: “İngiltere, Katalan bölgesel parlamentosu tarafından yapılan Tek Taraflı Bağımsızlık Bildirgesini tanımıyor ve tanımayacak. Bağımsızlık kararı, İspanya Anayasası'na göre yasa dışı ilan edilen bir oylamaya dayanıyor. Hukukun üstünlüğünün gözetildiğini, İspanyol Anayasası'na saygı duyulduğunu ve İspanyol birlik ve beraberliğinin korunduğunu görmek istiyoruz" (Saeed, 2017). İngiltere ile sıkıntılı bir süreç yaşayan özerk bölge İskoçya'dan ise, Katalan Parlamentosunun tek taraflı bağımsızlık ilanını tanıdığına yönelik herhangi bir açıklama gelmese de Katalonya'ya destek verdiği yönünde bir açıklama gelmiştir. İspanya'nın bağımsızlığa karşı çıkma hakkı olabileceğini ifade eden İskoçya Kültür, Turizm ve Dış İlişkiler Bakanı Fiona Hyslop, her şeye rağmen Katalonya'nın kendi geleceğini belirleyebilmesi gerektiğini vurgulamıştır. Madrid'in Katalan hükümetiyle gerekli ölçüde diyalog kurmadığını belirten Hyslop, tek taraflı olarak gerçekleştirilen bağımsızlık ilanının defalarca yinelenen diyalog çağrısının reddedilmesi üzerine geldiğinin altını çizmiştir (AB haber, 2017).

Angela Merkel'in sözcüsü Steffen Seibert, Twitter'da yaptığ 1 açıklamada, Alman federal hükümetinin böyle bir bağımsızlık ilanını tanımadığını belirterek, İspanya'nın egemenliği ve toprak bütünlüğünün dokunulmazlığına vurgu yapmış, diyalog için mevcut tüm fırsatların kullanması çağrısında bulunmuştur. Fransa Cumhurbaşkanı Emmanuel Macron da söz konusu süreç ile ilgili olarak Rajoy ve İspanyol hükümetine tam destek verdiğini açılamış, Fransız Guyanası ziyareti sırasında gazetecilere Fransa için İspanya'da tek muhatabın Başbakan Rajoy olduğunu söylemiştir. Macron, “İspanya'da anayasal kurallara sahip bir hukuk devleti mevcut. Mariano Rajoy bu kurallara uyulmasını istiyor ve benim buna tam desteğim var" diyerek Katalan Parlamentosunun tek taraflı bağımsızlık ilanına yönelik tavrını ortaya koymuştur (Aljazeera, 2017).

Belçika Başbakanı Charles Michel ise siyasi bir kriz olarak gördüğü bu durumun ancak diyalog yoluyla çözülebileceğini vurgulamış, ulusal ve uluslararası düzene saygılı bir barışçıl çözüm istediklerini ifade etmiştir (Saeed, 2017). Portekiz Başbakanı Antonia Costa da 
İspanya'nın anayasada yer alan birlik ve bütünlük ilkesinin savunusunda Madrid hükümeti ile tam dayanışma içinde olduklarını belirtmiştir (AB haber, 2017). Kanada Başbakanı Justin Trudeau, ülkesinin birleşik İspanya'yı tanıdığını, bu sebeple taraflar arasında gerçekleşmesi muhtemel müzakerelerin hukukun üstünlüğüne, İspanya anayasasına ve uluslararası hukuk ilkelerine göre yapılması gerektiğinin altını çizmiştir (Aljazeera, 2017).

14. Valdai Uluslararası Müzakere Kulübü toplantısında konuşan Rusya Devlet Başkanı Vladimir Putin ise Katalan Parlamentosunun aldığı tek taraflı bağımsızlık kararının İspanya'nın kendi iç meselesi olduğunu ve bu sorunun İspanyol mevzuatı ve Anayasası'na göre çözülmesi gerektiğini ifade ederek, bu türden konularla ilgili konuşulurken dikkatli olunması gerektiğini belirtmiştir (Kremlin, 2017). Tüm büyük uluslararası aktörler gibi Çin de, 2017 Ekiminde gerçekleştirilen referanduma ve hemen ardından Katalan hükümeti tarafından yapılan bağımsızlık ilanına karşı çıkmıştır. İspanyol hükümetinin toprak bütünlüğünü korumak için aldığı önlemleri destekleyen Pekin, meselenin AB Parlamentosu gündemine alınması için gayret sarf etmiştir. Buradaki amaç, AB'nin Katalan ayrılıkçılara yönelik İspanya'nın güç kullanımını kabul etmesinin sağlanması ve dolayısıyla bu güç kullanımın Çin'in anavatan ayrılıkçılarıyla başa çıkmasına izin veren bir emsal oluşturmasına imkân tanıması olmuştur. Ancak tüm siyasi kargaşa beklentilerine rağmen Çin'in Katalonya ile olan ticari faaliyetlerinin artması, örtülü olarak Çin'in Katalan bağımsızlığını bir tehdit olarak algılanmadığı anlamına da gelebilir (Moreno, 2019).

NATO Genel Sekreteri Jens Stoltenberg ise İspanya'nın, NATO güvenliğine önemli katkıları olan sadık bir müttefik olduğunu vurgulamış, Katalonya'nın bağımsızlık sorununun İspanya'nın anayasal düzeni içinde çözülmesi gerektiğinin altını çizmiştir (AB haber, 2017). Türkiye Cumhuriyeti Dışişleri Bakanlığı da Katalonya'nın bağımsızlık ilanının akabinde, "Anayasal meşruiyete sahip olmayan söz konusu tek taraflı kararda israr edilmemesini, demokrasi dikkate alınarak ve hukukun üstünlüğü temelinde çözüm bulunmasını temenni etmekteyiz. İspanya'nın toprak bütünlüğüne ve İspanya halkının iradesine saygıyı esas olarak görmekteyiz" şeklinde açıklama yapmıştır. Açıklama kapsamında Türkiye'nin, İspanya hükümet ve kurumlarının bu zorlu süreci aşacağından kuşku duymadığı ve bu doğrultudaki çabalarını desteklediği vurgulanmıştır (Dünya Haber, 2017). Türkiye'de Kanal 24'e verdiği röportajda Avrupa Birliği Bakanı Ömer Çelik, Katalan parlamentosunun bağımsızlığı ilan etme kararını "yanlış" olarak nitelendirmiştir. Röportajda Türkiye'nin Katalonya'nın bağımsızlık ilanını meşru bulmadığının altını çizen Çelik, “Türkiye, İspanya'nın toprak bütünlüğünü, anayasasını ve siyasi birliğini desteklemeye devam edecek" ifadeleriyle sözlerine devam etmiştir (Aljazeera, 2017).

\section{Sonuç ve Değerlendirme}

1 Ekim 2017'de gerçekleşen Katalan bağımsızlık referandumunu takiben Katalonya Parlamentosu'nun İspanya'dan tek taraflı bağımsızlık ilan etmesi sonrasında, birçok devlet meseleye tepki göstermiştir. Katalanların bağımsızlık ilanının diğer ayrılıkçı bölgeleri özendirme ihtimali ve dolayısıyla devletlerin toprak bütünlüğünün ve ülkesel birliğinin bozulma olasılığının güçlenmesi meselenin uluslararası alanda yankı uyandırmasının en önemli sebebi olarak görülebilir. Örneğin, Çin'in bölgeye çok uzak bir devlet olmasına rağmen Katalonya'nın bağımsızlık ilanı ile ilgili olumsuz görüş bildirmesi, kendi içindeki ayrılıkçı hareketlere (Şincan, Tibet, İç Moğolistan) yönelik tavrının net bir göstergesi olmuştur. Keza $\mathrm{AB}$ de bünyesi içindeki diğer ayrılıkçı hareketlere (Bask Bölgesi, Flaman Bölgesi, Korsika, Bavyera, Güney Tirol vb.) örnek olacağı ve dolayısıla AB 
entegrasyonunun engelleneceği düşüncesiyle bu bağımsızlık kararına karşı çıkmakta ve Katalonya'yı yalnızca İspanya'nın bir parçası olarak tanıdığını ifade etmektedir.

ABD ise Katalonya'nın bağımsız olmasının ortaya çıkaracağı domino etkisinin Batı'daki dengeleri değiştirme ihtimalini göz önüne alarak, Katalonya'nın İspanya bünyesindeki konumunun korunmasını istemektedir. Türkiye de kendi sınırları içinde yaşanan Kürt sorunu dolayısıyla ayrılıkçı bir bölgenin tek taraflı olarak bağımsızlık ilan etmesine sıcak bakmamakta ve İspanya merkezi hükümetinin yanında yer aldığını belirtmektedir. Rusya'nın tepkisinin ise diğer devletlere göre farklılık gösterdiğini söylemek mümkündür. Rusya, kendisine uzak bir bölgede vuku bulan bir gelişme olması nedeniyle duruma ilişkin olarak mesafeli bir duruş sergilemesinin yanı sıra meselenin İspanya'nın iç meselesi olduğunu vurgulamaktadır. Bu tavrından hareketle, Rusya'nın Batı'yı kendi iç sorunlarıyla mücadele eden bir formda görmek istediği ve bu nedenle Katalonya'nın bağımsızlık ilanını pek de olumsuz karşılamadığı söylenebilir.

Bu bilgiler ışığında, Katalan Parlamentosu'nun tek taraflı bağımsızlık ilanına yönelik verilen uluslararası tepkiler değerlendirildiğinde, devletlerin çoğunun genel olarak meseleye olumsuz baktıkları dikkat çekmektedir. Tek taraflı olarak ilan edilen bağımsızlığı tanımadıklarını ve İspanya merkezi hükümetinin yanında olduklarını belirten İngiltere, Almanya, Fransa, Belçika, Kanada, Türkiye ve ABD gibi devletler söz konusu bağımsızlık ilanının kendileri açısından bir şey ifade etmediğini vurgulasalar da, İspanya hükümeti tarafından referandumu engellemeye yönelik gerçekleştirilen şiddet eylemlerini kınamışlardır. Sorunun İspanya anayasası çerçevesinde hukukun üstünlügü gözetilerek çözülmesi gerektiğine vurgu yapan devletler, İspanya merkezi hükümetinin bölgesel hükümet ile diyalog kurmasının önemine de atffta bulunmuşlardır. Ancak Çin, İspanya hükümetinin toprak bütünlüğünü korumaya yönelik aldığı tüm önlemleri desteklediğini ifade ederek, şiddet eylemlerinin karşısında yer alan bir söyleme girmemiştir.

\section{Kaynakça}

AB Haber. (2017). Katalonya'nın bağımsızlık ilanına dünyadan ilk tepkiler...Bağımsızlık ilanı sonrası İspanya hükümeti, Katalonya parlamentosunu feshetti. Erişim Adresi https://www.abhaber.com/katalonyanin-bagimsizlik-ilanina-dunyadan-ilk-tepkiler/.

Aljazeera. (2017). World reacts as Catalonia calls for independence. Erişim Adresi: https://www.aljazeera.com/news/2017/10/world-reacts-catalonia-calls-independence171027221353 642.html.

Buchanan, A. E. (2007). Justice, legitimacy, and self-determination: Moral foundations for international law. Oxford University Press on Demand.

Cetrà, D., Casanas-Adam, E., \& Tàrrega, M. (2018). The 2017 Catalan independence referendum: A symposium. Scottish Affairs, 27(1), 126-143.

Child, D. \& Mitchell, C. (2017). Catalonia independence referendum: All you need to know. Erişim Adresi: https://www.aljazeera.com/news/2017/09/catalonia-independencereferendum-170927083751915.html.

Crawford, J. R. (2006). The creation of states in international law. Oxford University Press. 
Dewan, A., Cotovio V. \& Clarke, H. (2017). Catalonia independence referendum: What just happened?. Erişim Adresi, https://edition.cnn.com/2017/10/02/europe/cataloniaindependence-referendum-explainer/index.html.

Dünya Haber. (2017). Katalonya'nın bağımsızlık ilanına tepkiler. Erişim Adresi: https://www.dunya.com/dunya/katalonyanin-bagimsizlik-ilanina-tepkiler-haberi-388489.

DW News. (2017). Catalonia referendum violence prompts European reaction. Erişim Adresi: $\quad$ https://www.dw.com/en/catalonia-referendum-violence-prompts-europeanreaction/a-40772750.

Fabry, M. (2012). The contemporary practice of state recognition: Kosovo, South Ossetia, Abkhazia, and their aftermath. Nationalities Papers, 40(5), 661-676.

Kohen, M. G. (Eds.). (2006). Secession: international law perspectives. Cambridge University Press.

Kremlin. (2017). Meeting of the Valdai International Discussion Club. Erişim Adresi: http://en.kremlin.ru/events/president/news/55882.

Minder, R. (2017). Catalan Separatist Leaders Get Lengthy Prison Terms for Sedition. Erişim Adresi: https://www.nytimes.com/2019/10/14/world/europe/catalonia-separatistsverdict-spain.html.

Mix, Derek E. (2018). Spain and its relations with the United States: In brief. Congressional Research Service.

Moreno, M. V. (2019). China and the independence of Catalonia. Erişim Adresi: https://ceias.eu/china-and-the-independence-of-catalonia/.

Muro, D. (2017). Strategies of secession and counter-secession. Secession and Countersecession.

Real Instituto Elcano. (2019). The independence conflict in Catalonia. Erişim Adresi: http://www.realinstitutoelcano.org/wps/wcm/connect/d8496562-e096-44a1-81dab871c91ccf62/Catalonia-dossier-elcano-october2019.pdf?MOD=AJPERES\&CACHEID=d8496562-e096-44a1-81da-b871c91ccf62.

Saeed, S. (2017). How the world reacted to Catalan independence declaration. Erişim Adresi: https://www.politico.eu/article/how-the-world-reacted-to-catalan-independencedeclaration/.

Van den Driest, S. F. (2013). Remedial secession. A right to external self-determination as a remedy to serious injustices.

Weiss, B. (2017). Catalonia is an integral part of Spain': The US sides with Spain's government in Catalonia independence dispute. Erişim Adresi: https://www.businessinsider.com/us-catalonia-independence-spain-2017-10. 